\title{
Identity vs Role Confusion among Academic Dental Chairs in Pediatric Dentistry
}

\author{
VP Mathur ${ }^{1}$, G Kalra $^{2}$ \\ Journal of South Asian Association of Pediatric Dentistry (2019): 10.5005/jp-journals-10077-3033
}

The position of a departmental head/chair has been the most imperative and conscientious job, although the existing system of dental education in the South Asian region makes a faculty member as Head of Department by the virtue of number of availability of positions and number of years completed after their postgraduation (also called as teaching experience). Although the experience and number of publications are kept as records for such selections, more weightage is given to years of experience and lesser to research in the field and quality of teaching and administrative skills. The institutions where the postgraduate program is already established, the heads are supposed to mentor the academic, clinical, and research work for the postgraduates, and along with the same, they have to perform departmental administrative responsibility and human resource management., ${ }^{1,2}$

The designation of department chair is assigned to a faculty member on a particular day with no transition time for formal handover-takeover time. This transition is mostly sudden with no prior training and mentoring, leaving the individual in a state of identity vs role confusion as per the fifth stage of Erikson's psychosocial development theory. ${ }^{3}$ We have a strong tradition of clinicians who combine treating patients with academic research. However, many a times, due to lack of training, exposure, and mentoring, they remain in a state of confusion about their role similar to an adolescent facing the challenges of identity vs role confusion in the society. The person remains in a stage of thinking to whether start work for self-professional development or think about the growth of department. The academic training during postgraduation or later does not involve the components on how to be a mentor or administrator when you reach the positions of department chair. Neither there is a system of mandatory administrative or research training during their position as a faculty member nor it is a requirement for selection of department chair in many places.

The trends of setting up medical education units (MEUs) in medical institutes started in early 1990s with the aim of creating a unit which helps the newly appointed faculty members in learning effective teaching methodology and methods of objective assessment of the undergraduate and postgraduate students. ${ }^{4}$ The MEUs were also meant for training biomedical ethics and communication skills. Setting up of such units was made mandatory by the Medical Council of India but not by the Dental Council of India. Therefore, the Dental Institutes as part of Medical Colleges were benefitted by the MEUs, but isolated dental colleges did establish such facilities in most places. Moreover, there were not many takers for training in research and thesis mentoring in majority of dental institutions. Most of the dental institutions do not have a conducive research environment and training facilities for the faculty members. Furthermore, the general perception is that the
${ }^{1}$ Department of Pedodontics and Preventive Dentistry, Centre for Dental Education and Research, All India Institute of Medical Sciences, New Delhi, India

${ }^{2}$ Department of Pedodontics and Preventive Dentistry, Sudha Rustogi Institute of Dental Sciences, Faridabad, Haryana, India

Corresponding Author: Mathur VP, Department of Pedodontics and Preventive Dentistry, Centre for Dental Education and Research, All India Institute of Medical Sciences, New Delhi, India, Phone: +01126542491, e-mail: vijaymathur7@yahoo.com

How to cite this article: Mathur VP, Kalra G. Identity vs Role Confusion among Academic Dental Chairs in Pediatric Dentistry. J South Asian Assoc Pediatr Dent 2019;2(2):35-36.

Source of support: Nil

Conflict of interest: None

deans and administrative staff are not providing adequate support for the research until there is extramural funding. The number of funding agencies for medical research is limited and has limited budget. Sometimes, dental research also takes back seat in priority list for funding agencies.

Mentoring as a postgraduate thesis guide requires not only the knowledge of research methodology but also various other soft skills like team building, networking, conflict resolution, and strong analytic abilities. ${ }^{3}$ Furthermore, they should have a refined persona so that students perceive them as a mentor in them. It requires frequent monitoring, involvement, and abilities to detect problems at early stage and corrections. Some of the faculty members and department chairs learn the skills of thesis mentoring with time; however, a structured method of training for such tasks is lacking. There is a need to think in the direction of preparing the dental faculty for mentoring in research, teaching, and administrative skills.

Hence, formal "on-the-job-training" programs must be introduced in the dental schools which go beyond the general teaching and research methods. This would integrate the dental department chairs to integrate them in a desired role leaving behind their struggles and role confusion. This could be achieved with regular meetings, exchange of communication, and feedbacks from the dental professionals. However, becoming a leader in academics and research along with managing administrative skills must go hand in hand for an organized institutional functioning.

\section{References}

1. da Fonseca MA, Townsend J, Rodriguez T, et al. Characteristics and professional development needs of pediatric dentistry chairs in the United States and Canada. Pediatr Dent 2019;41(4):293-298. 
2. Rodriguez TE, Zhang MB, Tucker-Lively FL, et al. Profile of department chairs in U.S. and Canadian dental schools: demographics, requirements for success, and professional development needs. J Dent Educ 2016;80(3):365-373.
3. Erikson E. Childhood and Society. New York: Norton Publishers; 1950

4. Bhuiyan PS, Rege NN. Evolution of medical education technology unit in India. J Postgrad Med 2001;47(1):42-44. 